War Surgery of the Extremities

This is one of a short series of articles based on lectures given at the British Postgraduate Medical School, Hammersmith

\section{BLOOD TRANSFUSION}

BY

\section{JANET VAUGHAN, D.M., F.R.C.P.}

The problems of transfusion in wartime are inevitably different from those arising in peacetime. In wartime to a large extent we transfuse healthy individuals suffering from sudden severe injury. In peacetime we transfuse sick people. The following discussion applies to wartime transfusions only. It must be remembered, however, that knowledge of the pathology of haemorrhage and shock is extremely limited, and that the teaching of to-day must inevitably be revised as our understanding of the problems involved increases.

\section{Transfusion Fluids}

To-day the following fluids are available for transfusion: fresh blood, stored blood, plásma, serum, concentrated red cells.

Fresh Blood.-This has proved impracticable for use under airraid conditions. In the chaos of modern air raids or warfare it is impossible to call up and bleed donors. Transfusion fluids must be ready in store for immediate use or be brought in from outside the danger area at short notice. Fresh blood is essential for only a small group of chronic cases that do not need immediate treatment.

Stored Blood.--Experience has shown that blood taken into a - glucose-citrate mixture will store for fourteen to twenty-one days at low temperature $\left(2^{n}\right.$ to $4^{\circ} \mathrm{C}$.) without undue haemolysis taking place in vitro. The survival rate of transfused red cells is not appreciably lower than that of fresh blood. The reaction rate, provided the blood is warmed to $40^{\circ} \mathrm{C}$. before use, is no higher than with fresh blood (Brewer, Maizels, Oliver, and Vaughan, 1940). The diluent at present in general use is $100 \mathrm{c.cm}$. of $3 \%$ sodium citrate in distilled water, to which is added $20 \mathrm{c.cm}$. of $15 \%$ glucose in distilled water. The resulting $120 \mathrm{c.cm}$. is mixed with $420 \mathrm{c.cm}$. of blood (M.R.C. War Memorandum No. 1).

Plasma.-This may be prepared in three different formsunfiltered, filtered, and dried. Unfiltered plasma is prepared by siphoning the supernatant fluid off the red cells after sedimentation has occurred by standing or centrifugalization. It is a cloudy fluid which should be kept in the ice-chest. Filtered plasma is passed through a Seitz filter after separation. It is a clear fluid free from cell debris and the fatty content of unfiltered plasma. It must be kept at room temperature, as clotting will inevitably occur in the cold; unless great care is taken in filtration clotting is extremely likely to occur even at optimum temperatures. For the use of the Army, plasma is now being dried by a process similar to that employed for drying serum. The protein cortent of fluid plasma is only 4 to $5 \%$, owing to the presence of glucose-citrate diluent. The protein content of reconstituted dried plasma depends upon the amount of fluid added.

Serum.-Serum is also available in three forms-filtered, liquid, dry-and as serum citrate prepared from recalcified plasma (Clegg and Dible, 1940). Filtered serum is passed through a Seitz filter after separation of the clots. It is a clear amber fluid with a protein content of approximately $7 \%$. Dried serum is prepared by a modification of the method of Greaves and Adair (1939). It is reconstituted for use by the addition of either distilled water or normal saline, and may therefore be given in varying concentration, depending upon the amount of fluid added. Serum citrate is prepared by the addition of calcium to plasma and filtration of the resulting fluid through a Seitz filter.

Concentrated Red Cells.-This concentrated suspension is prepared by removing the supernatant plasma from the red cells so that double the usual amount of haemoglobin is given in the same volume of fluid. It is no more difficult to administer than whole blood, and is thought to give rise to fewer reactions (MacQuaide and Mollison, 1940).

Before discussing the relative values of blood, serum, and plasma it is necessary to consider the types of case that will need transfusion. They may be divided into acute and chronic conditions.

\section{Transfusion in Acute Cases}

The acute group may be roughly divided into three types: (1) patients with haemorrhage so severe as to result in anoxaemia ; (2) patients suffering from shock rather than blood loss ; and (3) patients with severe multiple injuries and considerable haemorrhage without obvious shock.

\section{Severe Haemorrhage}

In sudden severe haemorrhage there is a rapid fall in circulating haemoglobin, with resulting anoxaemia. It is then as essential to replace oxygen as it is to restore blood volume, and transfusions of whole blood are required. This type of case has proved rare as a result of air raids.

\section{Shock}

Shock is a term that includes a variety of conditions which are still poorly differentiated. I use it here to cover those states in which circulatory collapse, lowered body temperature, and pallor occur. It is usually considered to be associated with a fall in blood volume (Whitby, 1941). Treatment must therefore be directed to restoring blood volume. This can only be done by the use of liquids of high protein content. Saline is useless. Gum acacia was employed for this purpose in the last war, but it is difficult to prepare and is apt to cause liver damage. More recently it has been suggested that isinglass (fish gelatin) might be used (Taylor and Waters, 1941). Experimental work on the purification of animal proteins is in progress, but, so far, human plasma and serum have alone proved to be satisfactory for the purpose.

The evidence available suggests that fluid plasma, fluid serum, and dried serum are of equal therapeutic value in the treatment of shock (Vaughan and Brown, 1941). There are as yet few data available as to the effects of dried plasma. In this country no greater reaction rate has been recorded with serum and plasma than with blood. This observation is of some importance, as, with the exception of Levinson, Rubovits, and Necheles (1940), observers in the States regard serum as an almost lethal fluid. In this connexion it should be noted that, while we invariably pass serum through a Seitz filter, this is not done in the States. At the N.W. London Blood Supply Depot there are records of the administration of 147 pints of fluid serum with two mild reactions, and of 367 pints of filtered plasma, also with two mild reactions. Much larger quantities of both have been used in the area, but it is difficult to obtain accurate records under-raid conditions. It appears reasonable, however, to conclude that if severe reactions had occurred they would have been reported. In addition to the cases already recorded by Brown and Mollison (1940) we have further details of thirty-four bottles of reconstituted dried serum given without reaction.

Serum would seem to have certain practical advantages over plasma. It is easy to keep sterile, while plasma becomes readily infected. Serum does not clot, but hitherto it has proved extremely difficult to prevent plasma clotting either during or after filtration. The protein content of serum is higher than that of plasma. Further, serum is easy to handle, store, and transport. Plasma has one advantage over serum-namely, that out-of-date blood can be used for its preparation. It therefore seems probable that there is a place for both plasma and serum in any transfusion service.

For the purpose of discussion, cases of "shock" may be divided into three arbitrary groups: shock associated with multiple injuries other than crush injuries; shock associated with crush injuries; and shock associated with burns.

Shock associated with Multiple Injuries other than Crush Injuries. -In this condition there appears invariably to be lowered blood pressure unassociated with haemoconcentration. The pulse may be either rapid or slow. The only reliable guide to the success of any therapeutic measure has proved to be a maintained rise of blood pressure. It is impossible to lay down any hard-and-fast rule as to the dosage required to produce such a rise in pressure. Every case must be treated on its merits. Enough fluid must be given to raise the pressure and to maintain it at a level above $100 \mathrm{~mm}$. $\mathrm{Hg}$. No patient should be allowed to go to the operating theatre with a pressure that is much below $100 \mathrm{mg}$. It should be remembered that three or four pints of fluid, or more, may raise the pressure when one or two have failed. It would seem from our own 
published figures that many cases of circulatory collapse may be satisfactorily treated by blood derivatives, but whether, alone, they are preferable to whole blood remains to be seen. We have been struck by the occurrence of relatively low haemoglobin readings in patients with traumatic shock resulting from enemy action who have had no gross and obvious source of haemorrhage. Also, patients who have been successfully treated with plasma or serum have on subsequent examination shown haemoglobin readings in the neighbourhood of $60 \%$. Such preliminary observations suggest that the ideal treatment for a patient suffering from air-raid shock may be one or two bottles of plasma or serum followed by one or more bottles of blood, the treatment being controlled by repeated haemoglobin and blood-pressure readings. This procedure has been carried out successfully in a large number of recorded cases.

Shock associated with Crush Injury.-A series. of cases of crush injuries associated with renal failure have recently been described (Bywaters and Beall, 1941; Beall, Bywaters, Belsey, and Miles, 1941; Mayon-White and Solandt, 1941). The pathology of this condition is not for discussion here The treatment still remains uncertain and, with few exceptions, unsatisfactory (Longland and Murray, 1941; Henderson, 1941). It is important to remember that haemoconcentration in this condition may be pronounced. Figures as high as $160 \%$ have been recorded (Bywaters and Beall, 1941). It is obvious that in such a case serum or plasma should be used instead of whole blood. The amount to be given must be decided afresh for each case, the blood pressure and haemoglobin being used as the guide to dosage. The gross waterlogging of the tissues found at necropsy in some of these cases after massive saline transfusions suggests that saline is to be avoided.

Shcck associated with Burns.-Shock associated with severe burns is characterized by haemoconcentration, which may be severe. In a series of 13 cases of burns seen by Dr. Brown haemoconcentration was present in all those in which observations were possible, with one exception. In that case the patient was seen within twenty minutes of the injury. At this time both blood pressure and haemoglobin were within normal limits. Two pints of serum were given, and neither haemoconcentration nor fall of blood pressure occurred. It is, however, exceptional to see a patient so soon after injury. In burn shock, par excellence, there would seem to be a special call for the use of either plasma or serum, as fluid of a high protein content must be given to restore and maintain the blood pressure at a normal level. Repeated haemoglobin estimations may be impossible owing to the extent of the burnt area. If they can be done, however, they offer a valuable additional guide to dosage. Cases of burn, even if they have a normal pressure when first seen, should be immediately transfused; prevention is better than cure. Transfusions should begin before the patient is taken to the operating theatre to be cleaned up, and if the burnt area is extensive should be continued throughout this process and, if necessary, when he has returned to the ward. Subsequently intravenous therapy must be determined by the patient's condition.

\section{Severe Multiple Injuries and Haemorrhage}

Grant and Reeve (1941) described a group of cases in which there. was normal blood pressure in spite of severe multiple injuries and haemorrhage. Out of a group of 100 cases 28 presented this picture, and of these only 6 did not finally receive transfusion. In 13 cases the blood pressure fell considerably and the pulse rose within four hours of admission. In most the collapse occurred before operation, in a few it was delayed until during or after it. Transfusion was followed by rapid improvement. In 9 of the patients transfusion was started soon after admission, though the blood pressure was not low, and the condition remained satisfactory except when further bleeding occurred. As with burns, early transfusion prevents later collapse in severely injured cases. In other words, our guide in resuscitation work should be in the severity of the injury sustained and not the blood pressure or pulse level. Patients with multiple injuries and severe burns must be transfused as an urgent method of resuscitation. It is wiser to prevent circulatory collapse than to treat it. Patients in this group respond well to serum or plasma as an initial dose, but probably should receive blood in addition when it is available.

\section{Transfusion in Chronic Conditions}

The following two groups of patients require transfusions in the later stages of treatment: (1) those with burns, and (2) those with septic wounds.

Burns.-Localized oedema often occurs in the neighbourhood of a burnt area twenty-four hours after injury. There is some evidence that this may be reduced by the administration of twiceconcentrated or four-times-concentrated serum. It would appear wise to continue to give concentrated serum so long as oedema persists, unless the patient becomes intolerant of fluid by mouth; in such cases normal serum is preferable. In the late toxic stages, when sepsis has become an important factor, whole fresh blood should be given, if necessary, in large repeated doses by a drip technique. Satisfactory healing is dependent to a large extent upon maintaining an adequate haemoglobin level.

Septic Wounds.-Patients with infected wounds often show considerable anaemia. This is unaffected by the usual haemopoietic remedies (Vaughan and Saifi, 1939). Plasma proteins are also usually low. It is essential to raise both the haemoglobin and the plasma protein level in such patients if satisfactory wound-healing is to take place. This is done by repeated large transfusions of fresh whole blood. These transfusions should aim at raising the haemoglobin level to $100 \%$. Several pints may be given by drip technique during twenty-four to forty-eight hours. Having raised the haemoglobin it must be maintained at an optimum level. Concentrated suspensions of red cells are useful for this purpose, especially in elderly subjects in whom it is important not to increase the blood volume.

\section{Some Technical Points in Transfusion}

Temperature of Administration.-If circumstances permit it is wiser to warm blood, plasma, or serum to body temperature before administration. This can be done by standing the bloodbottle in water at $40^{\circ} \mathrm{C}$. for twenty minutes and mixing it gently at intervals. Under air-raid conditions it is often necessary to give the first bottle cold, but while this is being done the second can be warmed.

Rate of Administration.-With a young patient it is probably safer to give large quantities of fluid rapidly than it is with an older patient, but again it is difficult in our present state of knowledge to lay down any hard-and-fast rules for guidance. When the patient fails to respond to two pints of fluid administered rapidly, a careful watch should be kept on the base of the lungs if further rapid transfusion is considered. In practice we give the first two pints rapidly, using a reversed Higginson syringe to apply pressure if necessary, and subsequent fluid more slowly by drip technique. It should be remembered, when it is necessary to use the veins in the leg, that these are likely to be extremely collapsed, especially in the badly shocked patient, and that pressure is essential to start a flow of fluid. After the first pint the flow can usually be maintained by simple gravity.

Filtration.-Stored blood and derivatives should always be passed through a filter before administration. The routine administering unit in this country is fitted with such a filter. A fatality has recently been recorded in the States from giving unfiltered plasma (Mayner, 1941). At necropsy fibrin plugs were found in the lung capillaries.

Cross-matching.-It is the usual practice in this country at present to issue -universal donor blood only. Theoretically, therefore, it should not be necessary to cross-match the cells of the donor with the serum of the recipient. When possible, however, it is wise to do this, as errors in grouping cannot always be avoided and such a cross-match serves as a double check. In the case of serum and plasma no cross-matching is necessary. Both serum and plasma are prepared from pooled supplies, and it is found that as a result the agglutinin titre becomes either negative or so low as to be insignificant. Even in the early days of plasma transfusion in this country, before pooling was carried out, it was found that no ill effects followed the transfusion of a Group B donor, for instance, with large quantities of Group A plasma, and vice versa.

\section{Transfusion Reactions}

The ideal transfusion should have no effect on the patient beyond improvement ; reactions may, however, occur. They take various forms, varying considerably in severity. The mildest type shows a slight rise in temperature ; in others there is a severe rigor, often associated with a pain in the back, vomiting, and headache or generalized urticaria. In some instances in which incompatible or grossly haemolysed blood has been given there is a haemolytic crisis, resulting, unless promptly treated, in death. When a severe rigor occurs, the question at once arises whether the transfusion should be stopped. Every case must be decided on its merits; in a severely anaemic patient or a shocked air-raid casualty it is wiser to continue the transfusion in spite of the rigor. In the less acute case the transfusion may be stopped. 
In the case of an incompatible transfusion, prompt measures must be taken if the patient's life is to be saved. It is essential to maintain an alkaline urine. Alkali should be given by mouth and, if necessary, by intravenous injection. The patient should be catheterized twice a day if there is retention. It should not be assumed that failure to pass urine means complete anuria. Fluids, especially glucose solution, should be given in large quantities, if necessary per rectum or intravenously.

\section{Summary}

The use and relative value of whole blood, serum, and plasma for transfusion purposes are discussed.

Whole blood is preferred in acute severe haemorrhage; plasma and serum in conditions associated with haemoconcentration-i.e., burns and certain cases of crush injury; and a combination of plasma and serum, with whole blood, in patients with severe multiple injuries.

In the case both of burns and of injuries the severity of the injury and the degree of blood loss rather than the blood pressure and pulse should indicate the necessity for transfusion.

No rules for the precise dosage of any transfusion fluid can be laid down. It is essential to raise and maintain the blood pressure over $100 \mathrm{~mm}$. $\mathrm{Hg}$. The dose required to do this is extremely variable.

Serum and plasma appear of equal clinical value, and both are non-toxic. Serum has certain practical advantages over plasma.

\section{REFERENCES}

Beall, D., Bywaters,, E. G. L., Belsey, R. H. R., and Miles, J. A. R. (1941). British Medical Journal, 1, 432.

Brewer, H. F., Maizels, M., Oliver, J. O., and Vaughan, J. M. (1940). Ibid., 2, 48. Brown, H. A., and Mollison, P. L. (1940). Ibid., 2, 821

Bywaters, E. G. L., and Beall, D. (1941). Ibid., 1, 427

Clegg, J. W., and Dible, J. H. (1940). Lancet, 2, 294

Grant, R. T., and Reeve, E. B. (1941). British Medical Journal, 2, 293, 329.

Greaves, R. I. N., and Adair, M. E. (1939). J. Hyg., Camb., 39, 413

Henderson, R. G. (1941). British Medical Journal, 2, 197.

Levinson, S. O., Rubovits, F. E., jun., and Necheles, H. (1940). J. Amer. med. Ass., 115, 1163.

Longland, C. J., and Murray, J. (1941). Lancet, 2, 158

MacQuaide, D. H. G., and Mollison, P. L. (1940). British Medical Journal, 2, 555 Mayner, F. (1941). J. Amer. med. Ass., 116, 2015.

Mayon-White, R., and Solandt, O. M. (1941). British Medical Journal, 1, 434.

Taylor, N. B., and Waters, E. T. (1941). Canad. med. Ass. J., 44, 547.

Vaughan, J. M., and Brown, H. (1941). Proc. roy. Soc. Med., 34, 261.

Whitby, L. E. H. (1941). Proc. roy. Soc. Med., 34, 257.

\section{ACCELERATED MEDICAL COURSE AT TORONTO}

The acceleration of the medical course at the University of Toronto to meet the shortage of doctors for the armed Forces and for civilian needs was decided upon in the spring of 1941. The proposed curriculum consisted in lengthening the academic session from $7 \frac{1}{2}$ to 10 months in all years of the course but the first, which is made up of pre-medical subjects. This procedure will ensure that a class of students graduates every eight months instead of every twelve as at present. As it has been thought essential that each graduate should have a period of interneship in a hospital in order to round off his education, either to begin private practice or to become a medical officer in the Forces, the hospitals were asked if they would shorten the interneship period from 12 months to 8 months so that medical officers might be made available for military service as quickly as possible and at the same time provide for the

University of Toronto Course: Graduation, Interneship. Military Service

\begin{tabular}{|c|c|c|c|c|c|}
\hline \multirow{2}{*}{\multicolumn{2}{|c|}{$1941-2$}} & \multirow[b]{2}{*}{ Graduation } & \multirow[b]{2}{*}{ Interneship } & \multicolumn{2}{|c|}{ Available for Military Service } \\
\hline & & & & $\begin{array}{l}\text { Speeded-up } \\
\text { Course }\end{array}$ & $\begin{array}{l}\text { Regular } \\
\text { Course }\end{array}$ \\
\hline 6th Year & . & Apr. 30,1942 & May 1,1942 & Jan. 1, 1943 & July 1,1943 \\
\hline 5th Year & . & Dec. 31,1942 & $\begin{array}{c}\text { Dec. } 31,1942 \\
\text { Jan. } 1 \text { to } \\
\text { Aug. } 31,1943\end{array}$ & Sept. 1, 1943 & July 1,1944 \\
\hline 4th Year & .. & July 30,1943 & $\begin{array}{l}\text { Sept. } 1,1343, t: \\
\text { Apr. } 30,1944\end{array}$ & May 1, 1944 & July 1,1945 \\
\hline 3rd Year & . & Apr. 28, 1944 & May 1 to & Jan. 1, 1945 & July 1, 1946 \\
\hline 2nd Year & . & Dec. 31,1944 & $\begin{array}{l}\text { Jan. } 1 \text { to } \\
\text { Aug. } 31,1945\end{array}$ & Sept. 1, 1945 & July 1,1947 \\
\hline
\end{tabular}

co-ordination of the interneship period with the graduation of students every 8 months. Provincial licensing bodies were requested to permit the medical curriculum to be completed in a shorter time than their regulations required. Both the hospitals and the licensing bodies agreed to the proposed changes as a war measure.
The accelerated curriculum at Toronto came into operation when the second- to sixth-year classes registered on Aug. 25, 1941 , the effects of which are shown in the accompanying table. As the result of this speeded-up curriculum, the sixth-year class will take the place of the present class of internes in hospitals on May 1 instead of July 1, making them available for military service 2 months earlier than would ordinarily be the case. This present sixth-year class will be available for the Forces on Jan. 1, 1943, instead of July 1, or 6 months sooner; the fifth-year' class will be available 10 months, the fourth-year 14 months, the third-year 18 months, and the second-year 22 months earlier. The curricular changes in the courses of each of the years have been only of a minor character, the time-tables in each year consisting of the three terms of the present course, to which has been added the first term of the next succeeding year, in the fourth term from April to June. The total length of the actual instruction is such that each student receives practically the same sound medical training as in the regular course, but in a shorter period.

\section{Correspondence}

\section{Post-war Medical Reorganization}

SIR,-There are few members of the medical profession who will not have read, with interest and profit, the Interim Report of the Medical Planning Commission, to which document you have so rightly given first place in your issue of June 20. Being an interim report, published for the purpose of stimulating discussion within the profession, it is not comprehensive, and, for the same reason, the proposals contained in it are capable of amendment.

Writing as a member of the public health service I should like to express the view that the fundamental principles underlying the report, such as central control by the Ministry of Health or a similar body, and administration by enlarged local authorities or ad hoc regional bodies, are sound and worthy of support by the profession as a whole, including those engaged in the public services. It is, however, important, when the scheme has been fully discussed by the profession and is presented in its final form, that we should make up our minds which of the various alternatives we wish to support. Should the scheme be. administered centrally by the Ministry of Health or by a specially appointed body, and at the periphery by local authorities or by newly formed authorities created for this purpose only? These points are not matters of detail, as the success of any scheme involving such a complicated issue as the integration of all the present medical services into one complete system depends largely upon the suitability and competence of the bodies chosen to supervise and administer it.

The report itself suggests the answer to one of these questions when it emphasizes that "the system under which local authorities administer in detail a broad national policy decided by the central Government is deeply embedded in the social fabric of this country." This would seem to be a conclusive argument in favour of peripheral administration by enlarged local authorities appointed for all purposes, and there is the further reason that the present major authorities have already co-ordinated some of the medical services which are referred to in the report, including their hospitals, many of the personal health services, and the services concerned with environmental hygiene. Moreover, the influences favouring a satisfactory condition of health within the community are by no means wholly medical. Apart from questions of nutrition and standards of living, which are only slightly influenced by the action of local authorities, there are such matters as housing, education, the provision of baths and wash-houses, abattoirs, parks and recreation grounds, crematoria, etc., all of which in the hands of local authorities play a part in affecting favourably the health of individuals living in urban communities. On its merits the argument for allowing local authorities to take a share in the administration of the new medical service seems a sufficiently strong one ; but, apart from this, it would seem to be politically wise to enlist the support of the powerful influence of the local authorities in favour of the profession's agreed scheme rather than to risk disaster by provoking their equally powerful opposition. On the whole the major local authorities, if of sufficient size and possessing adequate rateable value, 